\title{
Metallic Droplet, Weld Pool Temperatures Evaluation and Pulsed Wave Formulation in the Pulsed GMAW ${ }^{1}$
}

\author{
Régis Henrique Gonçalves e Silva ${ }^{a}$, Rodrigo Rodrigues Nogueira ${ }^{a}$ (D), Fernando Lucas dos Santos e Silva ${ }^{b}$ \\ Arthur Gustavo Moreira Santos ${ }^{c}$, Uallas Henrique de Oliveira de Brito ${ }^{a}$ \\ ${ }^{a}$ Universidade Federal de Santa Catarina (UFSC), Centro Tecnológico, Trindade, CEP 88040-900, \\ Florianópolis, SC, Brasil. \\ ${ }^{b}$ Universidade Federal do Rio de Janeiro (UFRJ), Centro de Tecnologia, Cidade Universitária, Av. \\ Athos da Silveira Ramos, 149, CEP 21941-909, Rio de Janeiro, RJ, Brasil. \\ ${ }^{c}$ Universidade Federal de Uberlândia (UFU), Av. João Naves de Ávila, 2121, Campus Santa Mônica, \\ CEP 384000-902, Uberlândia, MG, Brasil.
}

Received: February 19, 2020; Revised: October 8, 2020; Accepted: October 15, 2020

\begin{abstract}
This study analyzed the average temperature value of the metallic droplets and weldpool of the Pulsed GMAW welding process using 309L-Si electrode as the addition metal. The study was based on the formulation and evaluation of pulsed waves, starting from the equation of energy constant (or detachment constant), and waveforms from two commercial welding sources, that were evaluated and reproduced. The technique of filming by high speed infrared radiation was used for evaluation. The results point to a higher droplet temperature for a lower intensity of pulse current, due to longer dwell time at this level, and also revealing that a longer time in the base phase may be responsible for a further heating of the fusion pool.
\end{abstract}

Keywords: Droplet, temperature, pulsed, GMAW, waveform.

\section{Introduction}

Studies related to health and safety in industrial environments have contributed to reducing much of the risks in welding processes. Specifically related to the generation of fumes, is known that this phenomenon is associated with the level of temperature reached by the droplets' surface while they are projected inside the plasma column in a welding process. Temperature is one of the most used variables in the process control industry in the most diverse segments. In this context, the objective of this study is to estimate the surface temperature of the metallic droplet and weldpool of a Pulsed GMAW process using the infrared radiation technique with the help of a high-speed thermographic camera.

The essence of the Pulsed process equation was obtained in a study focused on the selection of pulsed current parameters in GMAW welding using 309L-Si stainless steel wire deposited on plate evaluating a mathematical model ${ }^{1-3}$ for the Pulsed process waveform equation. The model shows that the energy required for the formation of the metallic drop will depend on the current pulse parameters, and will obey the equation $D \geq$ $I_{p}{ }^{\mathrm{x}} \cdot t_{p}$. That is, from the relationship between pulse time $\left(\mathrm{t}_{\mathrm{p}}\right)$ and pulse current $\left(\mathrm{I}_{\mathrm{p}}\right)$ raised to an exponent " $\mathrm{x}$ ", it is possible to find the detachment constant for the tested material ${ }^{1-3}$. In addition, $\operatorname{Amin}^{1}$ mentions in his study that for this equality

${ }^{1}$ This paper was presented in the 10th Brazilian Congress on Manufacturing Engineering, August 2019, São Carlos / SP

*email: rodrigo.nogueira@posgrad.ufsc.br to prevail, the exponent used must be kept with the value of $2.3^{1}$. Dutra ${ }^{3}$ admits the best exponent 1.83 for the ER-4043 wire, and other authors cite the exponent value $2.0^{2}$.

Analyzing the model and results presented by these authors, one perceives the possibility of the formation and detachment of the metallic drop at different levels of current and pulse time, which implies processes and droplets with different levels of energy involved. In addition, the variation in the exponent value adopted can be perceived according to the addition metal used.

This analysis and comparison seeks to verify the influence of the parameters and the shape of the current wave on the temperature of the metallic drop and the melting pool.

\section{Materials and Methods}

To perform the tests, an experimental bench was set up, consisting mainly of a welding source, a wire feeder, an automatic GMAW welding torch, a linear movement system for the torch, a data acquisition system and a thermal high speed camera. The welding sources used was a DIGITec 300, by IMC $\left(\right.$ Soldagem ${ }^{4}$. Voltage, current and wire speed data were acquired in all tests, using the Sistema de aquisição Portátil (SAP) from IMC Soldagem ${ }^{5}$, that works in an acquisition rate of $5 \mathrm{kHz}$. For the torch movements, a Tartílope V2 by SPS Soldagem ${ }^{6}$ was used to manipulate the welding torch. The temperature measurement was performed with the 
camera of filming of images in wavelength in the infrared field. The SC7000 model from FLIR $\AA$, that is able to make image acquisition up to $62000 \mathrm{~Hz}^{7}$, was used.

For the first analysis four sets of parameters of Pulse current, Base current, Pulse time and Base time $\left(I_{p}, I_{b}, t_{p}\right.$ and $t_{b}$, respectively) were evaluated using a previously raised square waveform which ones all their set of pulsed wave form parameters resulted in an average current value of 150A. Subsequently, waveforms from Fronius CMT Advanced $400 R$ and OTC DW300 were investigated.

In order to obtain the temperature of the droplets without interference of the electric arc, the desired waveforms were configured with moments in which the electric arc is extinguished immediately after the end of the pulse (and the beginning of the base) with the intention to prevent the luminosity of the arc from negatively influencing thermographic footage. The time the arc kept extinguished comprises from the imminence of detachment of the droplet to its impingement on the weld pool, preferably. As all periods of the waveforms used revolve around $20 \mathrm{~ms}$, was estimated that $3 \mathrm{~ms}$ was a reasonable time for the arc to remain extinct and the readings performed. Thus, an acquisition rate of $1481 \mathrm{~Hz}$ was configured so that a frame was obtained every $0.68 \mathrm{~ms}$, meaning that a droplet detachment and its whole translation was recorded by at least four frames.

The first analysis was focused on reproducing the welding procedures in a stable manner using all the different pulse current parameters previously raised. Based on aforementioned method, the equation for the constant of energy defined was evaluated using a methodology in which the process parameters were varied in order to determine an exponent $x$ that would promote the detachment of the metallic droplet during the base time of the pulsed wave. The exponent is determined according to the detachment condition of a droplet per pulse (ODPP condition), the moment of detachment and the range of currents to which it allows the application. Two exponents were estimated that obey the proposed relation and promove a stable and constant transfer for this wire and conditions, they being 3.17 and 1.79. It was verified a wider range of parameters variation when the smaller exponent was used, ensuring a more stable process for lower and upper current limits.

The second analysis of the study consists of acquiring and reproducing waveforms from Fronius ${ }^{\circledR}$ CMT Advanced 400R and OTC $®$ DW300 DC commercial welding sources. For reasons of abbreviation these will be called in this work Fronius and OTC, respectively. Both methodologies aim to quantify the average temperature value of the surface of the metal droplets and in the melt pool.

With the acquiring the waveform from their respective manufacturers, a strategy was adopted so as not to mischaracterize the original waveform of the manufacturer. Such strategy consists of raising a cloud of points which represents the current as a function of time. Due the greater complexity existing in the waveform imposed by the Fronius, it was divided into 17 parts in order to guarantee a greater representation of its shape. It was necessary only 5 points to reproduce the OTC pulsed waveform. Figure 1 and 2 represents the point cloud created to reproduce the acquired waveforms for both Fronius and OTC.
The method used to determine ER309L-Si wire emissivity was based on elevating its temperature until it was close to its melting point and capture the whole process with the thermographic camera. Through the software data analysis, the emissivity value of a region of interest can be adjusted by observing its temperature value. The method is illustrated in Figure 3. The emissivity was adjusted recursively so that the result of the average temperature of the monitored region coincided with the melting temperature of stainless steel 309L-Si obtained in the literature ${ }^{8,9}$.

In order to reduce the possible measurement errors introduced by the reflection of the electric arc on the surface of the highlighted droplet, the current waveform was modified in order to extinguish the arc for a short period of time ( $3 \mathrm{~ms})$ right after the pulse of current. In this way, the droplet can be observed in its trajectory towards the melting pool without the luminous and thermal influence of the electric arc, thus

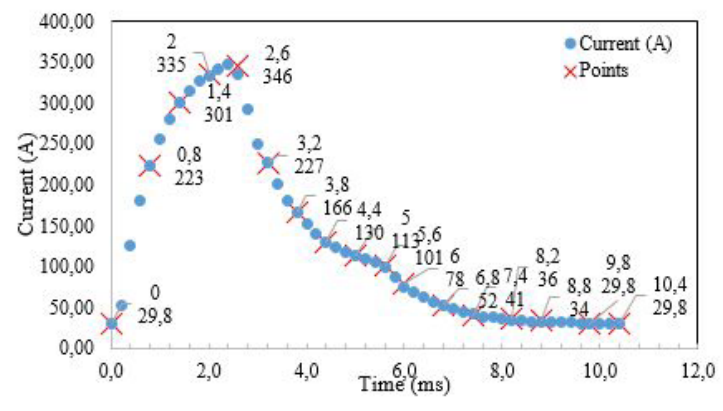

Figure 1. Fronius GMAW pulsed waveform.

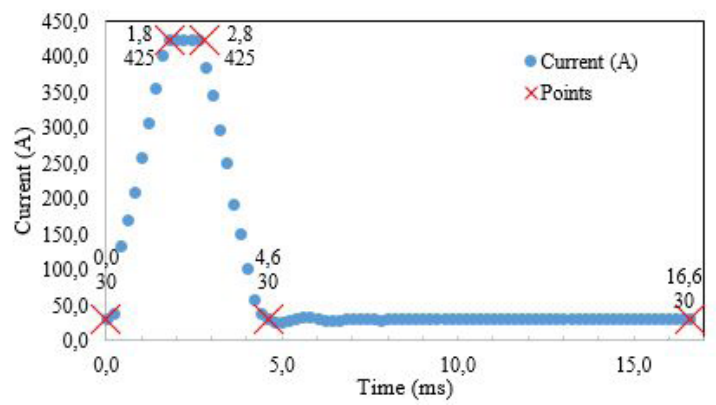

Figure 2. OTC GMAW DC pulsed waveform.

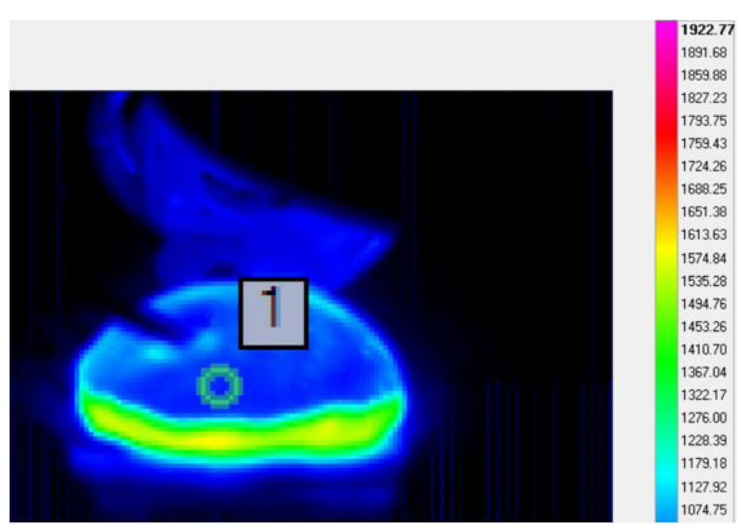

Figure 3. [1] Melted 309L-Si filmed for determination of his emissivity. 
resulting in a more reliable result. The measurement action of the droplet surface and weld pool temperatures during the time the arc is extinct is shown in Figure 4.

Initially four tests were performed to evaluate the variation of the exponent $x$, with two conditions of Pulse current for each exponent, 1.79 and 3.17. Two tests were performed with waves acquired from their respective manufacturers (Fronius, OTC), one for each waveform. The deposits were made on ASTM 304L stainless steel plate in the flat position and $90^{\circ}$ torch angle. The distance between the contact tip and the workpiece was adjusted to $20 \mathrm{~mm}$. The shielding gas, composed of $95 \% \mathrm{Ar}, 3 \% \mathrm{CO}_{2}$ and $2 \% \mathrm{~N}_{2}$, was adjusted to a flow rate of $18 \mathrm{l} / \mathrm{min}$. Image acquisition by the thermographic camera was performed at a rate of $1481 \mathrm{~Hz}$. The parameters inserted in the welding source it is in Table 1.

The Fronius Power Source presents a little pulse of current before de Base current that called Tail pulse current (Ipat). Theoretically, this pulse is to ensure the droplet detachment. Disregarding the time the arc is off $\left(\mathrm{t}_{\text {off }}\right)$, all tests resulted in an average current value of $150 \mathrm{~A}$. This study intends to conclude about the droplets surface temperature difference between the ones projected from different pulse currents and different waveforms. The adopted methodology requires manual delineation of thermographic image regions that corresponds to the droplet in transition, and it means the measurement process becomes very susceptible to the operator's influence. As a way of minimizing this influence, it was decided that all measurements had to be carried out by three operators, individually, but following the same procedure. This way, a better representation of the real value is statistically obtained.

\section{Results and Discussions}

Figures 5 and 6 represents the reproduction of the waves acquired from the Fronius and OTC welding sources and performed on the DigiTec 300 welding source.

The emissivity value of 309L-Si steel was previously defined experimentally as 0.18 , corroborating with the data available in the literature ${ }^{8,9}$ for this temperature range. After conducting statistical analysis involving temperature measurement from 30 random droplets by each one of the three operators, the data obtained were organized, synthesized and displayed in Table 2 and 3.

The results of the performed thermographic measurements can be compared to each other in different ways like within the exponent itself (varying pulse intensities and times) or between exponents (varying the "energy constant" D). In addition, the obtained data allows us to compare the synergic program from Fronius ${ }^{\circledR}$ manufacturer and the GMAW Pulsed from OTC manufacturer, that is, comparing different waveforms.
When comparing the droplets surface temperatures values considering the intensity and pulse time of the rectangular used waveforms, that is, when the exponent is fixed (and, consequently, the detachment constant D is also fixed) and pulse configurations vary (time and intensity) it is
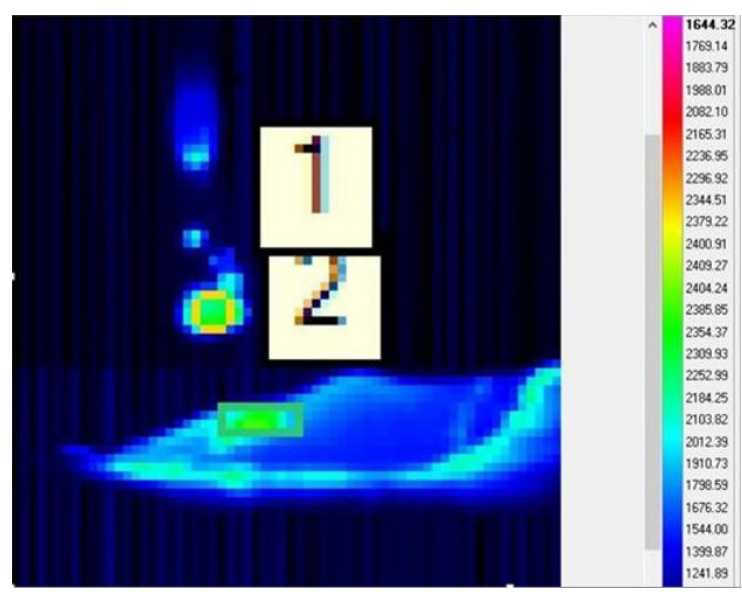

Figure 4. Highspeed infrared footage of [1] Detached droplets that fall into [2] weldpool without the luminous and thermal influence of the electric arc.

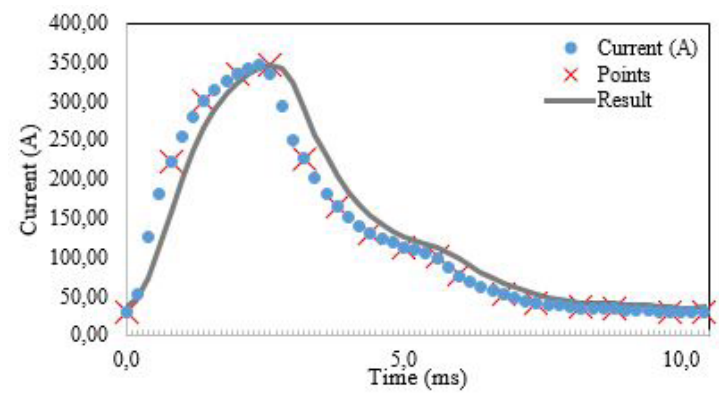

Figure 5. Result Fronius GMAW pulsed waveform.

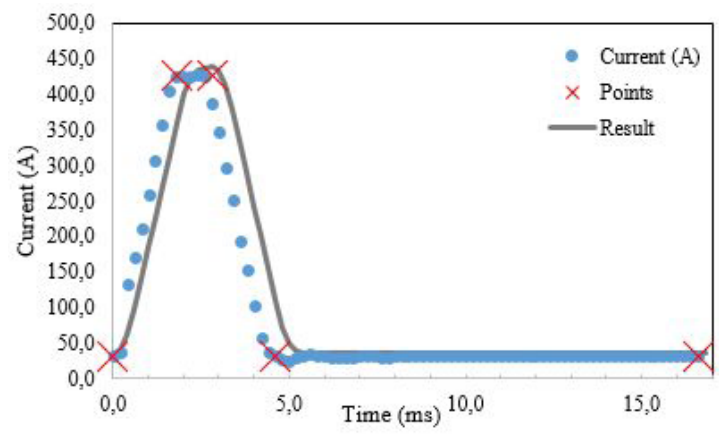

Figure 6. Result OTC GMAW pulsed waveform.

Table 1. Parameters for different pulsed wave.

\begin{tabular}{lllll}
\hline \multirow{2}{*}{ Exp 1,79} & $\mathrm{Ip}=245 \mathrm{~A}$ & $\mathrm{tp}=5 \mathrm{~ms}$ & $\mathrm{Ib}=91 \mathrm{~A}$ & $\mathrm{tb}=8 \mathrm{~ms}$ \\
\cline { 2 - 5 } & $\mathrm{Ip}=450 \mathrm{~A}$ & $\mathrm{tp}=1,7 \mathrm{~ms}$ & $\mathrm{Ib}=105 \mathrm{~A}$ & $\mathrm{tb}=11,3 \mathrm{~ms}$ \\
\hline \multirow{2}{*}{ Exp 3,17} & $\mathrm{Ip}=270 \mathrm{~A}$ & $\mathrm{tp}=4,3 \mathrm{~ms}$ & $\mathrm{Ib}=90 \mathrm{~A}$ & $\mathrm{tb}=8,7 \mathrm{~ms}$ \\
\cline { 2 - 4 } & $\mathrm{Ip}=370 \mathrm{~A}$ & $\mathrm{tp}=1,6 \mathrm{~ms}$ & $\mathrm{Ib}=119 \mathrm{~A}$ & $\mathrm{tb}=11,4 \mathrm{~ms}$ \\
\hline OTC & $\mathrm{Ip}=425 \mathrm{~A}$ & $\mathrm{tp}=1 \mathrm{~ms}$ & $\mathrm{tp} a \mathrm{~A}=4,0 \mathrm{~ms}$ & $\mathrm{Ib}=30 \mathrm{~A}$ \\
\hline Fronius & $\mathrm{Ip}=346 \mathrm{~A}$ & $\mathrm{tp}=2,9 \mathrm{~ms} \quad \mathrm{Ipat}=100 \mathrm{~A}$ & $\mathrm{tb}=3,7 \mathrm{~ms}$ \\
\hline
\end{tabular}


Table 2. Droplet temperatures

\begin{tabular}{|c|c|c|c|c|c|c|c|}
\hline & & \multicolumn{2}{|c|}{ Exp. 1,79} & \multicolumn{2}{|c|}{ Exp. 3,17 } & \multirow{2}{*}{ Fronius } & \multirow{2}{*}{ OTC } \\
\hline & & $\mathrm{Ip}=245 \mathrm{~A}$ & $\mathrm{Ip}=450 \mathrm{~A}$ & $\mathrm{Ip}=270 \mathrm{~A}$ & $\mathrm{Ip}=370 \mathrm{~A}$ & & \\
\hline \multirow{2}{*}{ Operator 1} & Average $\left({ }^{\circ} \mathrm{C}\right)$ & 2278 & 2199 & 2245 & 2157 & 2184 & 2178 \\
\hline & Standard deviation $\left({ }^{\circ} \mathrm{C}\right)$ & 33 & 29 & 29 & 29 & 25 & 31 \\
\hline \multirow{2}{*}{ Operator 2} & Average $\left({ }^{\circ} \mathrm{C}\right)$ & 2253 & 2170 & 2250 & 2278 & 2258 & 2296 \\
\hline & Standard deviation $\left({ }^{\circ} \mathrm{C}\right)$ & 34 & 18 & 17 & 30 & 22 & 20 \\
\hline \multirow{2}{*}{ Operator 3} & Average $\left({ }^{\circ} \mathrm{C}\right)$ & 2270 & 2243 & 2256 & 2228 & 2220 & 2340 \\
\hline & Standard deviation $\left({ }^{\circ} \mathrm{C}\right)$ & 41 & 62 & 44 & 46 & 49 & 43 \\
\hline \multicolumn{2}{|c|}{ Average $\left({ }^{\circ} \mathrm{C}\right)$} & 2267 & 2204 & 2250 & 2221 & 2221 & 2271 \\
\hline \multicolumn{2}{|c|}{ Standard deviation $\left({ }^{\circ} \mathrm{C}\right)$} & 36 & 41 & 33 & 36 & 34 & 34 \\
\hline
\end{tabular}

Table 3. Weld pool temperatures

\begin{tabular}{|c|c|c|c|c|c|c|c|}
\hline & & \multicolumn{2}{|c|}{ Exp. 1,79} & \multicolumn{2}{|c|}{ Exp. 3,17} & \multirow{2}{*}{ Fronius } & \multirow{2}{*}{ OTC } \\
\hline & & $\mathrm{Ip}=245 \mathrm{~A}$ & $\mathrm{Ip}=450 \mathrm{~A}$ & $\mathrm{Ip}=270 \mathrm{~A}$ & $\mathrm{Ip}=370 \mathrm{~A}$ & & \\
\hline \multirow{2}{*}{ Operator 1} & Average $\left({ }^{\circ} \mathrm{C}\right)$ & 1572 & 1855 & 1831 & 2129 & 1979 & 1826 \\
\hline & Standard deviation $\left({ }^{\circ} \mathrm{C}\right)$ & 30 & 34 & 31 & 31 & 26 & 62 \\
\hline \multirow{2}{*}{ Operator 2} & Average $\left({ }^{\circ} \mathrm{C}\right)$ & 1534 & 1842 & 1857 & 2112 & 2112 & 1781 \\
\hline & Standard deviation $\left({ }^{\circ} \mathrm{C}\right)$ & 47 & 69 & 84 & 113 & 29 & 66 \\
\hline \multirow{2}{*}{ Operator 3} & Average $\left({ }^{\circ} \mathrm{C}\right)$ & 1854 & 1752 & 1839 & 1827 & 1744 & 1800 \\
\hline & Standard deviation $\left({ }^{\circ} \mathrm{C}\right)$ & 27 & 31 & 66 & 42 & 33 & 53 \\
\hline \multicolumn{2}{|c|}{ Average $\left({ }^{\circ} \mathrm{C}\right)$} & 1653 & 1816 & 1842 & 2023 & 1945 & 1802 \\
\hline \multicolumn{2}{|c|}{ Standard deviation $\left({ }^{\circ} \mathrm{C}\right)$} & 37 & 50 & 66 & 77 & 29 & 61 \\
\hline
\end{tabular}

possible to observe that 6 out of 7 cases indicate that longer (consequently, less intense) pulse times tend to expel warmer droplets and vice versa - shorter pulses tends to expel colder droplets, even if they use a higher intensity. But, on the other hand, the choice of different exponents (which necessarily generates different $D$ 's) does not significantly change the expelled droplets surface temperature. This behavior can be observed in the graphs in Figure 7 and 8.

Regarding the weld pool temperature the opposite is observed. The longer the droplet detachment time, the lower the temperature of the pool. On the other hand, the shorter the droplet detachment time, the higher the temperature of the weld pool. This dynamic can be observed in Figures 9 and 10 .

Such behavior happens due to the fact that the droplet absorbs a considerable amount of energy during its detachment and, considering waves with the same period, if a longer time for the detachment occurs, there is less time for the system to input heat exclusively to the weld pool. Likewise, if the droplet takes longer to detach, there is less time in the wave period for which the system will input heat exclusively to the weld pool, causing it to not reach such high temperatures. On the other hand, it is possible to observe a significant difference in the melt pool when different exponents are used. It is a fact, elucidated above, that different pulse times and intensities influence the temperature of the weld pool. However, the graphs in Figure 9 and Figure 10 show that, for a $95 \%$ confidence factor, even with the choice of equivalent intensity and pulse time settings, the use of different exponents provides melt pools with different temperatures.

Another way to analyze the results obtained in the experiments is to consider both the intensity and the pulse time at once multiplying both quantities and thus obtaining the amount of charge that flows through the electrode at each pulse. It is possible to observe that the droplet temperature increases as the number of charges present in a single pulse

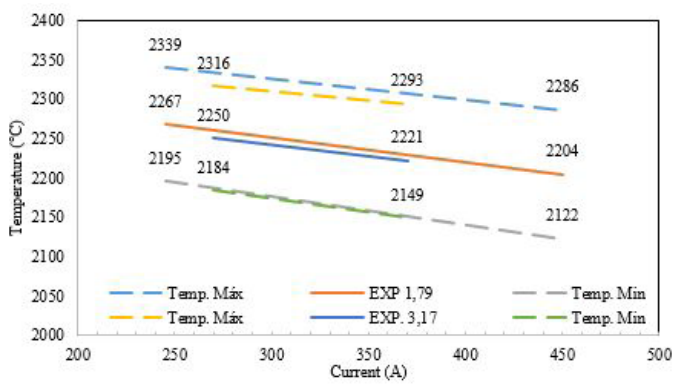

Figure 7. Droplet temperature versus Pulse current.

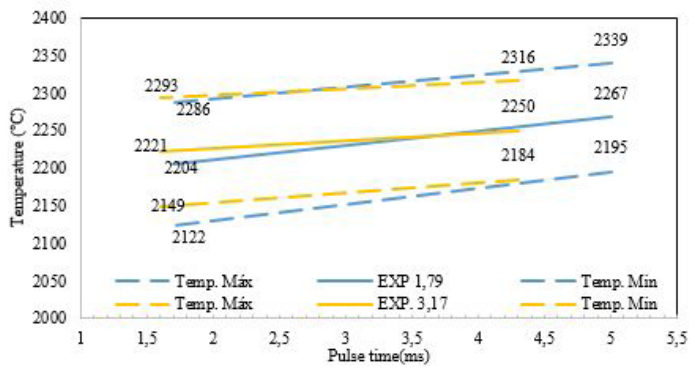

Figure 8. Droplet temperature versus pulse time.

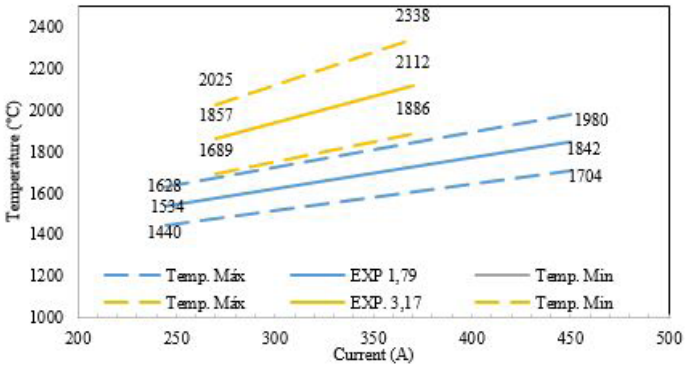

Figure 9. Weld pool temperature versus Pulse current. 


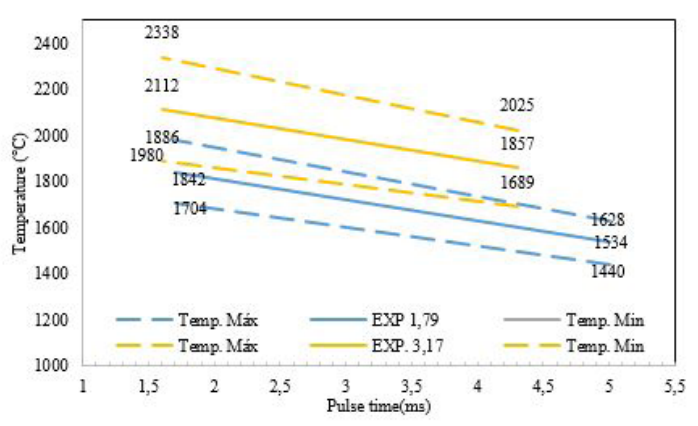

Figure 10. Weld pool temperature versus Pulse time.

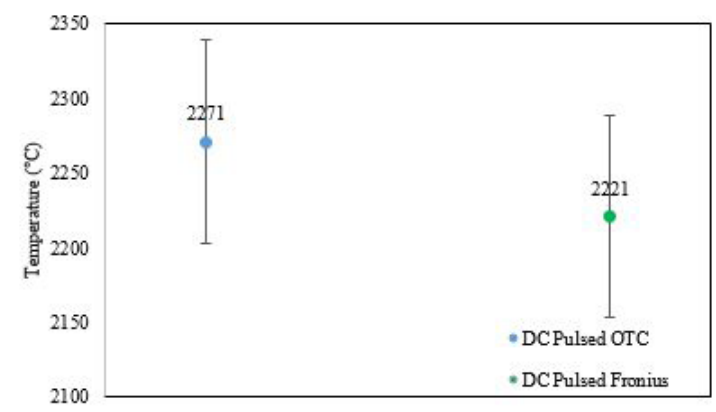

Figure 11. Droplet temperature - Fronius and OTC Pulsed GMAW.

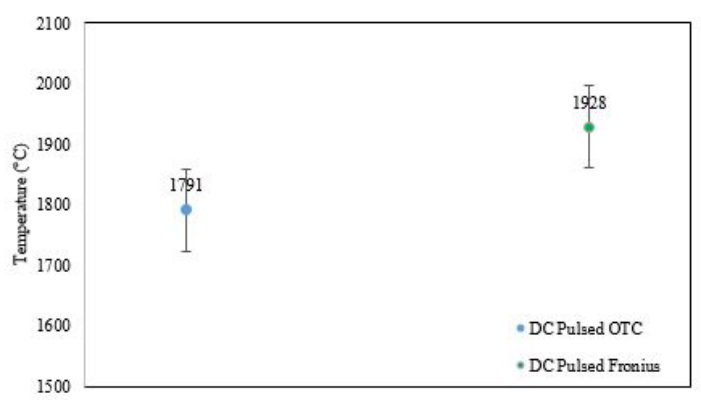

Figure 12. Weld pool temperature - Fronius and OTC Pulsed GMAW.

also increases. On the other hand, the temperature of the pool decreases as loads are present on the pulse. Assuming that the amount of charges belonging to a complete period is the same because the average current is always the same, it is possible to conclude that the temperature of the droplets varies directly proportional to the amount of charges destined for the pulse.

When comparing the droplets surface and melt pool temperatures generated by the OTC Pulsed GMAW and Fronius Pulsed GMAW processes, the difference between it is minimal, and it is not possible to observe a significant difference in the temperature from the droplets expelled from each of them, as illustrated in Figure 11.

But, when comparing OTC Pulsed GMAW and Fronius Pulsed GMAW processes it is possible to observe a significant difference in the temperature from the weldpool from each of them, as illustrated in Figure 12. This difference can be attributed for the wave form of the synergic program from
Fronius ${ }^{\circledR}$, that has a little Pulse current before the the Base current called Pulse current at tail (Ipat).

\section{Conclusions}

The analysis in pulsed GMAW processes demonstrate that there is a correlation between the pulse configuration (intensity and time) and the temperature of both the droplet surface and the melting pool. This correlation demonstrates that the use of longer pulses tend to expel warmer droplets for exposing them to high current intensities for longer periods and, consequently, the weld pool for shorter amount of time when compared to the use of shorter pulse time. The use of shorter pulses, in turn, decrease the droplet high intensity current exposure time and increase the time the weld pool is exposed to the arc without droplet formation increasing, this way, the likelihood of the droplets reaching lower temperatures and the weld pool higher ones.

Another observation made in this study correlates the exponent value for the definition of Detachment Constant "D" and the temperature of the melting pool. This correlation shows the use of the largest exponent, understood as a "more energetic" one, appeared accompanied by melting pools with higher temperatures despite the droplets (temperatures) remain the same. This is due the fact that, physically, the same amount of energy is always needed to detach a droplet of wire and, if one configuration has more energy than the other, the spare energy is added over the pool that in its turn is transformed into heat.

Analyzing the temperatures from the weldpool and metallic droplets of process using waveforms from Fronius $\AA$ CMT Advanced 400R and OTC $®$ DW300 DC power sources is not possible to observe a significant difference in the temperature from the droplets expelled from each of them but is possible to observe a difference in the temperature from the weldpool from each of them. This difference can be attributed to the waveform of the Fronius ${ }^{\circledR}$ synergistic program, which has a non-square waveform. This wave presents pulse time as being punctual and can be considered smaller, when compared to the OTC wave. Another factor that may influence this difference is the second pulse current, defined as the Tail pulse current, from the Fronius synergistic program. It is worth noting that the wave of the Fronius synergistic program also has a lower frequency of detachment when compared to the current wave of OTC.

\section{References}

1. Amin M. Pulse current parameters for arc stability and controlled metal transfer in arc welding. Metal Construction. 1983;15(5):272-8.

2. Dutra JMCSR. Consonâncias e dissonâncias interpretativas no inter-relacionamento das variáveis da corrente pulsada aplicada. Soldag Insp. 2012;17:201-9.

3. Lesnewich A. A control of melting rate and metal transfer in gas-shielded metal-arc welding part I. Weld J. 1958;suppl:343-53.

4. IMC Soldagem. DIGIPlus A7 - Manual [Internet]. [cited 2017 Dec 10]. Available from: http://www.imc-soldagem.com.br/ pt-br/manuais

5. IMC-SOLDAGEM. IMC soldagem [Internet]. [cited 2017 Dec 10]. Available from: http://www.imc-soldagem.com.br/media/ com_eshop/attachments/manual_SAP\%20V4_4aEd.pdf 
6. SPS. SPS Sistemas e Processos de Soldagem [Internet]. [cited 2017 Dec 10]. Available from: http://www.sps-soldagem.com. br/tartilope_v2.php

7. FLIR. FLIR SC7200 series: state-of-the-art infrared technology for R\&D/science [Internet]. [cited 2017 Nov 11]. Available from: http://www.flirmedia.com/MMC/THG/Brochures/RND_017/ RND 017 US.pdf
8. AKSteel. 309/309s - Datasheet [Internet]. [cited 2017 Sep 16]. Available from: http://www.aksteel.com/pdf/ markets_products/stainless/austenitic/309_309s_data_sheet. pdf

9. Sif W. 309LSi - Datasheet [Internet]. [cited 2017 Sep 16]. Available from: http://www.weldability-sif.com/media/pdfs/ info/WO340840.pdf 